\title{
¿Conseguirá la UNESCO a través de la Declaración de Florencia dar sitio en la agenda mundial a "la cultura"?
}

La tercera edición del foro mundial de la UNESCO sobre la cultura y las industrias culturales reunió el pasado mes de octubre en Florencia (Italia) a 300 representantes de los sectores público y privado del mundo cultural con objeto de debatir sobre el papel de la cultura como motor de desarrollo. "Creo que los países deben invertir en cultura con la misma determinación con la que invierten en recursos energéticos, en nuevas tecnologías (...) En un contexto de crisis económica, es preciso -afirmaba la directora general de la UNESCO, Irina Bokova, en la apertura del foro- encontrar de nuevo motores de cohesión, y la cultura ofrece respuestas".

Isabel Luque Ceballos | Centro de Formación y Difusión, Instituto Andaluz del Patrimonio Histórico

URL de la contribución <www.iaph.es/revistaph/index.php/revistaph/article/view/3606>

La Declaración de Florencia ${ }^{1}$ surge en el contexto del foro mundial sobre la cultura y las industrias culturales. Se trata de la tercera edición de una serie de encuentros organizados por la UNESCO, el gobierno de Italia, la región de Lombardía y la ciudad de Monza, en los dos primeros casos, y de Florencia, en el tercero. Las anteriores ediciones se centraron en el diálogo de los sectores público y privado sobre el papel de la cultura en el desarrollo (2009) y en las industrias de la edición y la lectura (2011). El III foro amplía el marco de pensamiento y acción, porque entre sus objetivos se encuentra situar la cultura en la agenda de desarrollo post-2015. De esta forma da continuidad a la trayectoria de la UNESCO iniciada con Nuestra Diversidad Creativa ${ }^{2}$ y con la convención de 2005 sobre la Protección y la Promoción de la Diversidad de las Expresiones Culturales ${ }^{3}$, en la que se defiende el acceso a la cultura como un derecho de la ciudadanía y, por tanto, un elemento más en el desarrollo y crecimiento de los pueblos.

En esta línea, se citaron en el foro como antecedentes "la edición especial del Informe de la Economía Creativa 2013, co-publicado por la UNESCO, el Programa de Desarrollo de las Naciones Unidas (PNUD), y las resoluciones de las tres Asambleas Generales sucesivas de la ONU sobre cultura y desarrollo (2010, 2011 y 2013), que reconocen el papel de la cultura como un facilitador e impulsor de las dimensiones económicas, sociales y ambientales del desarrollo sostenible".
En resumen, un gran esfuerzo y trabajo conjunto, que no parece haber tenido a lo largo de su trayectoria un reflejo claro en las políticas internacionales. Ahora se plantea una nueva oportunidad para situar realmente la cultura en la agenda política internacional.

Junto a la defensa general de la cultura como elemento necesario para el desarrollo sostenible de los pueblos, los puntos de la Declaración tratan los siguientes temas:

> la coordinación de la sociedad civil y el sector privado en el diseño de las políticas culturales, bajo el paraguas de la gobernanza;

$>$ la creatividad como elemento clave en el desarrollo de zonas urbanas y rurales, desde políticas culturales y

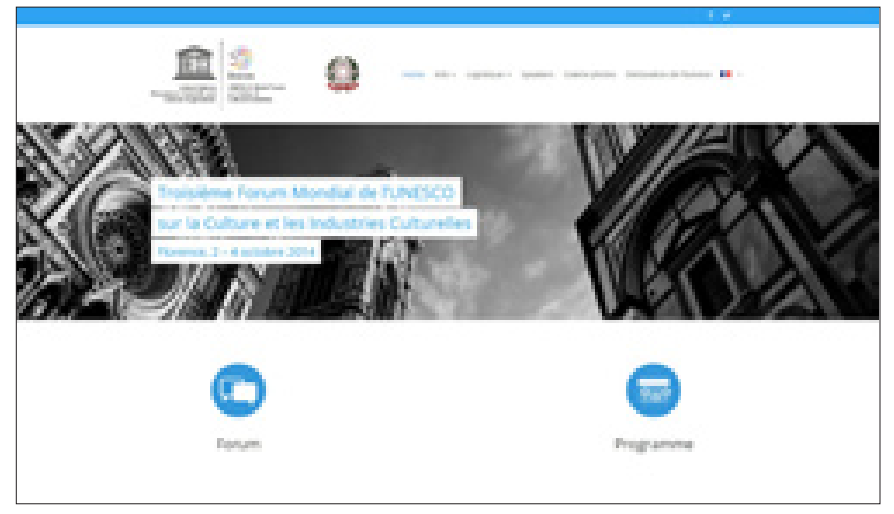

Sitio web del III Foro sobre cultura e industrias culturales <http://www.focus2014 org/> 
medio ambientales sostenibles;

> la movilidad de artistas y creadores sin fronteras;

$>$ modelos de educación inclusiva y de calidad, desde el derecho a la vida cultural;

$>$ la creatividad como oportunidad de desarrollo social, etc.

Haciendo una retrospectiva sobre los temas propuestas, encontramos debates anteriores sobre estos puntos en distintos foros nacionales e internacionales. Por ejemplo, Xavier Greffe hablaba ya en el 2003 sobre patrimonio cultural y desarrollo y, en el 2010, sobre la importancia de las ciudades creativas ${ }^{4}$. Posteriormente, el Banco Interamericano de Desarrollo (BID) impulsa la publicación La Economía Naranja: Una oportunidad infinita (2013), manual de uso de la creatividad cultural para el desarrollo en América Latina y el Caribe ${ }^{5}$.

\section{Presencia en la agenda internacional}

La combinación de los conceptos cultura, desarrollo, innovación, creatividad, sostenibilidad, etc., se viene trabajando desde hace tiempo y -de hecho- existen ejemplos y casos prácticos de estas aplicaciones desde lo local. Lo novedoso es que este pensamiento tenga un protagonismo claro en las políticas internacionales, en una agenda global donde la cultura, a pesar de los esfuerzos de la UNESCO, no ha pasado de ser una anécdota, frente a la programación finalista de los problemas de la humanidad, según los enunciados de los objetivos del milenio.

Destaca esta apuesta en un contexto en el que precisamente la cultura, como otros sectores, ha sufrido las consecuencias del desmantelamiento progresivo de lo público y del estado del bienestar. La inclusión de esta bajo el epígrafe economicista de industria cultural la ha llevado, por una parte, a una revalorización en el mercado; por otra, a ser equiparada con otros sectores productivos y considerada dentro del sistema en cadena, sin que se diferencie entre las pequeñas iniciativas -que son realmente los puntos de partida de la creatividad y la innovación, además de las garantes de la pluralidad y la diversidad de la vida cultural- y los grandes mecanismos de producción en serie que explotan esa creatividad. Además de ser una fuente de ingresos o gastos, ante todo la cultura es un derecho ciudadano ${ }^{6}$.
Esperemos que la convención de Florencia ayude a dimensionar la cultura como un derecho legítimo de los ciudadanos, de interés general para todos los pueblos, y no como un lujo al que sólo puede acceder una pequeña parte de la humanidad.

\section{NOTAS}

1. Declaración de Florencia, 4 de octubre de 2014: <http:// unesdoc.unesco.org/images/0023/002303/230394s.pdf> [Consulta: 24/02/2015]

2. Nuestra Diversidad Creativa <http://portal.unesco. org/culture/es/ev.php-URL_ID=22431\&URL_DO=DO_ TOPIC\&URL_SECTION=201.html>

3. Convención de 2005 sobre la Protección y la Promoción de la Diversidad de las Expresiones Culturales <https:// es.unesco.org/creativity/> [Consulta: 24/02/2015]

4. GREFFE, X. (2003) ¿Es el Patrimonio un incentivo para el desarrollo? PH Boletín del IAPH, n. ${ }^{\circ} 42$, Especial Monográfico: Patrimonio y desarrollo. Y también Greffe, Xavier ¿Qué es una ciudad creativa? Disponible en <http://www.globbtv.com/30/microsite/446/que-es-unaciudad-creativa> [Consulta: 24/02/2015]

5. Disponible en <http://publications.iadb.org/bitstream/ handle/11319/3659/La\%20economia\%20naranja\%3a \%20Una\%20 oportunidad\%20infinita. pdf?sequence=4> [Consulta: 24/02/2015]

6. Como bien dice Alfons Martinell, la mayoría de las políticas culturales no se han basado en los derechos humanos, ni en los derechos fundamentales. ¿Por qué hemos trabajado un modelo de cultura basado más en el Estado de derecho que en los derechos humanos, cuando todos tenemos derecho a la vida cultural? (Curso "Modelos de gestión de proyectos e instituciones culturales", organizado por el Instituto Andaluz de Administración Pública y la Secretaría General de Cultura, Consejería de Educación, Cultura y Deporte, Junta de Andalucía, 12-14 de mayo 2014, IAPH Sevilla). 